porated the No. 2 carbon of malonate into one or more of the identified acids-malate, citrate, succinate, or fumarate. In view of the large number and diversity of species performing this incorporation, it is suggested that the enzyme(s) capable of metabolizing malonate may be widespread throughout the plant kingdom.

LELAND M. SHaNnON ROGER H. YOUNG Carlton Dudley

Department of Horticultural Science,

University of California,

Los Angeles 24. Dec. 23.

${ }^{1}$ Bentley, L. E., Nature, 170, 847 (1952).

${ }^{2}$ Nelson, E. K., and Hasselbring, H., J. Amer. Chem. Soc., 53, 1040 (1931).

${ }^{3}$ Young, R. E., and Biale, J. B., Plant Physiol., 31 (Supp.), 23 (1956).

- den Dooren de Jong, L. E., Dissertation, Rotterdam (not seen) (1926).

Hayaishi, O., J. Biol. Chem., 215, 125 (1955).

- Wolfe, J., Iuler, D. , and Rittenberg, S., J. Biol. Chem. ,209,867 (1954).

${ }^{7}$ Nakada, H., Britton, B., and Wolfe, J., Fed. Proc., 16, 93 (1957).

${ }^{8}$ Nakada, H., Wolfe, J., and Wick, A., J. Biol. Chem., 228, 145 (1957).

- Giovanelli, J., and Stumpf, P. K., Plant Physiol., 32, 498 (1957)

${ }^{10}$ Young, R. H., and Shannon, L. M., Plant Physiol., 33 (Supp.), 35 (1958).

11 Brady, R. O., Proc. U.S. Nat. Acad. Sci., 49, 933 (1958).

\section{Micro-volume Drop-plate Assay of} Antibiotics

IN assaying antibiotic substances by any of the well-known plate diffusion methods it is necessary to dilute the unknown solution to varying degrees, depending on the original concentration. In addition to minimizing the possible disturbing influence of interfering substances and the $p \mathrm{H}$ of the original sample in the assay plate, this procedure has the practical convenience of providing inhibitory zones of a suitable size-range needed for a satisfactory assay. However, if one could run good assays on the original concentrated samples without resorting to serial dilution it would simplify the assay procedures. We have found that such a step is possible with the use of a micrometer syringe which would enable one to spot micro-volumes directly on the assay plate with great accuracy. These minute volumes dry rapidly and form discrete spots, giving uniformly circular inhibition zones after allowing proper diffusion and incubation periods.

In order to test the practicability of the outlined approach, several four-point assays were run on liquid samples containing penicillin by both the conventional cup-method and the micro-volume drop-plate method, the latter with the aid of a micrometer syringe ('Agla' brand, Burroughs Wellcome and Co.). In both cases the plates were prepared according to the enriched seed layer method described by the U.S. Food and Drug Administration ${ }^{1}$, using 'Difco Penassay' base and seed agars. The assay organism was Bacillus subtilis A.T.C.C.6633. In the droplet method, in place of cups, the same volumes of a suitable penicillin $G$ standard and the unknownusually, 0.4 and $1.6 \mu \mathrm{l}$., corresponding to two and eight small divisions on the peripheral scale of the micrometer head-were spotted directly on the agar surface. Assay values were calculated from the resulting inhibition zones using Miyamura's nomogram ${ }^{2}$.

Results of the assays given in Table 1 show that the droplet method as used by us is quite satisfactory, and the errors involved cannot be considered to be higher than in the commonly used cup, cylinder and bead-modifications of the plate assays. In our experience, the method is simpler than these other conventional plate methods and less time-consuming,
Table 1. Penicillin Titres OF UNKNowns in Units/ML.

\begin{tabular}{|c|c|c|}
\hline Sample No. & Cup-plate assay & $\begin{array}{c}\text { Micro-volume } \\
\text { drop-plate assay }\end{array}$ \\
\hline 1 & 1,020 & 1,010 \\
2 & 2,020 & 2,000 \\
3 & 2,180 & 2,390 \\
4 & 1,860 & 1,840 \\
5 & 1,910 & 2,050 \\
6 & 2,740 & 1,700 \\
7 & 1,590 & 1,940 \\
9 & 1,650 & 1,551 \\
& & 1,683 \\
\hline
\end{tabular}

as highly concentrated unknowns can be used directly in the assay plate. The method has no material disadvantages except, perhaps, the increased concentration and care required of the operator while adding small volumes represented by one or two small divisions on the peripheral scale of the micrometer head. However, with the addition of a semi-automatic addition mechanism such as the one described earlier ${ }^{3}$, this method is capable of being developed into a good routine tool for assaying not only antibiotics but also other compounds which are physiologically active in agar plate methods involving micro-organisms or cell-lines.

Further evaluation of the method is being published in detail elsewhere.

I am indebted to Dr. A. H. Amin, director of research, for the encouragement he has given me in this work. I also wish to acknowledge the technical assistance of colleagues in the microbiological research laboratory.

Microbiological Research Laboratory,

Alembic Chemical Works Co.,

Baroda. Jan. 12.

1 "The Compilation of Tests and Methods of Assay for Antibiotic Drugs", U.S. Federal Security Agency, Food and Drug Administration, 1 (1954).

${ }^{2}$ Miyamura, S., Antibiotics and Chemotherapy, 6, 658 (1956).

'Glynn Jones, G. D., and Lowe, H., J. Lab. Practice, 5, 69 (1956).

\section{- Incidence of the Erythrocytic Defect associated with Drug-Sensitivity among Oriental Subjects}

IN the past few years a new type of metabolic lesion of the red cell has been elucidated. It was found that sensitivity to the hæmolytic action of the 8-aminoquinoline primaquine and many other compounds was due to an intrinsic defect of the red cell ${ }^{1}$. This defect can be demonstrated in vitro by : (1) incubating the red cells with a solution of acetylphenylhydrazine and observing the pattern of Heinz body formation ${ }^{2}$, and (2) incubating the red cells with acetylphenylhydrazine or a number of other substances and measuring the level of reduced gluta. thione after an incubation period of $2 \mathrm{hr}$. (the glutathione stability test) ${ }^{3}$, or (3) measuring the activity of the enzyme glucose-6-phosphate dehydrogenase in the red cells ${ }^{4}$.

It has been known for some time that sensitivity to drug-induced hæmolysis varies considerably in different racial groups. Application of these in vitro techniques has disclosed marked differences in the incidence of this red-cell defect in various population groups. Thus, the defect is common in American Negroes, but rare in most Caucasian populations. It is relatively common in Sardinia, and in Israel has been found to occur commonly in Sefardic, but not in Aschkenazy Jews. As might be expected, the incidence of drug-induced hæmolytic anæmia and favism 